\title{
Are students prone to depression and suicidal thoughts?
}

\author{
Ewa H. Mojs ${ }^{1}$, Katarzyna Warchoł-Biedermann ${ }^{1}$, Maria D. Głowacka ${ }^{2}$, Wojciech Strzelecki ${ }^{1}$, \\ Beata Ziemska³, Włodzimierz Samborski ${ }^{4}$
}

1Department of Clinical Psychology, Poznan University of Medical Sciences, Poznan, Poland

2Department of Health Sciences, Poznan University of Medical Sciences, Poznan, Poland 32Department of Occupational Medicine, Poznan University of Medical Sciences, Poznan, Poland

4Department of Physiotherapy, Rheumatology and Rehabilitation, Poznan University of Medical Sciences, Poznan, Poland

Submitted: 25 June 2013

Accepted: 16 July 2013

Arch Med Sci 2015; 11, 3: 605-611

DOI: 10.5114/aoms.2013.38179

Copyright $\odot 2015$ Termedia \& Banach

\begin{abstract}
Introduction: Depression may affect up to $9.8 \%$ of adolescents and young adults and is associated with significant life-long consequences. The aim of our study was to assess the association between symptoms of depression and demographic factors such as gender, having brothers or sisters, background (rural/small town or urban permanent place of residence), perceived financial status, current living arrangements, year and major area of study.

Material and methods: One thousand one hundred eighty-three students of medical or similar faculties, $71 \%$ of whom were females, anonymously answered the Kutcher Adolescent Depression Scale (KADS) and completed a demographic questionnaire.

Results: We found that $6.5 \%$ of all participants $(n=77)$ had depression according to Kutcher's criteria whereas $1.5 \%$ of them $(n=18)$ reported suicidal thoughts. We also observed the influence of such factors as gender $(p<0.009)$, year $(p<0.001)$, major area of study ( $p<0.034)$, and financial status ( $p<0.000-0.003)$, on depression scores. Moreover, depressive symptomatology was most frequent in subjects who were only children, in freshmen and in students of psychology $(11.5 \%$, $13.2 \%$ and $16.7 \%$ respectively). However, we did not observe an impact of such agents as students' permanent place of residence $(p=0.929)$ or current living arrangements on depressive symptoms $(p=0.940)$.

Conclusions: Susceptibility to depression fluctuates throughout the course of study and depends on factors associated with the study itself such as the student's major or year of study and other socio-demographic agents, i.e. gender or self-reported financial status.
\end{abstract}

Key words: depression, prevalence, psychological test, student.

\section{Introduction}

Depression, which is a very common mental disorder and a global public health concern, often starts at an early age. Currently it is estimated that it may affect up to $9.8 \%$ of adolescents and young adults [1-3]. This condition is associated with significant consequences such as chronicity and suicide. A link between depression, suicidal thinking and suicidal behavior has often been implicated. In fact, studies have documented that the majority of young suicide victims had depression at the time of death

\author{
Corresponding author: \\ Ewa Helena Mojs PhD \\ Department \\ of Clinical Psychology \\ Poznan University \\ of Medical Sciences \\ 70 Bukowska St. \\ 60-812 Poznan, Poland \\ E-mail: ewamojs@ump.edu.pl
}


$[2,4-7]$. Also, most adolescent suicide attempt survivors were diagnosed with symptoms of clinical depression at the time of their attempt. Additionally, data in the literature have shown that high prevalence of depressive symptoms in youth was associated with an increased risk of chronic or recurrent depression in adult life [2, 3, 8-10]. Finally, depressive symptoms such as poor motivation, concentration problems, exhaustion or aversion to activity were often connected with poorer social and occupational functioning, i.e. could cause disability. Because of the importance of depression, several investigations have been devoted to the examination of its risk factors. So far a number of correlates of early depression such as gender, socioeconomic status and subject's family characteristics have been analyzed [11-18]. Some papers suggested that youth depression could be triggered by negative or stressful life events such as starting university study [19-22]. Here, attention was paid to the relatively high prevalence of depressive symptoms in the population of university students. Some authors have asserted that student depression should be analyzed separately because the period of time spent at a university is a time of transition when an adolescent has to go through many physical and mental changes before he becomes an adult. They also noted such phenomena as high susceptibility to depression in medical students or indicated the role of economic problems or difficulties with cultural, environmental or academic adjustment [21, 23-25]. Yet the results of research sometimes remain arguable, so a deeper insight into the phenomenon of student depression and its determinants may facilitate a better understanding of the problem [15]. We used Kutcher's KADS to evaluate depressive symptoms in students living in Poznan, Poland.

We also assessed the association between depression and subject's major, the role of reported socio-economic status within one faculty of study, and the association between susceptibility to depression and subject's year of study.

\section{Material and methods}

A total of 1183 participants of the study who were 18-24 years old (mean age $=21.0 ;$ $\min =18$; $\max =24 ; S D=1.98)$ and mostly females $(71 \%)$, were recruited among students enrolled at Poznan University of Medical Sciences or Adam Mickiewicz University in Poznan. They anonymously and voluntarily answered a questionnaire on symptoms of depression (KADS - the Kutcher Adolescent Depression Scale) and followed instructions to select the best answer on the 0-3 scale ( 0 - hardly ever, 1 much of the time, 2 - most of the time, 3 - all of the time). KADS, which is a self-report scale and a screening tool designed to evaluate severity of depression in young people, consists of six statements on sadness, hopelessness, tiredness, difficulties of life, worry and suicidal thoughts. This test assumes that anyone who scores six points or above may have or is at risk of depression [26]. The internal consistency of KADS as measured by Cronbach's $\alpha$ reached 0.84 . Correlations between test items as measured by Pearson $r$ ranged from 0.35 to 0.66 [25]. Additionally, all subjects completed a demographic questionnaire which comprised questions on their age, gender, having brothers or sisters, background (rural/small town or urban permanent place of residence), perceived financial status, current living arrangements, their year and major area of study. They were examined individually in conditions ensuring that their privacy and confidentiality were duly protected. The participants were informed about the purpose and importance of the study and the investigator made sure subjects knew they could stop the interview at any moment. The design and methods used in the study were approved by the Bioethical Commission of Poznan University of Medical Sciences (Decision No. 19/08).

\section{Statistical analysis}

The results were collected using Excel spreadsheets so that evaluations of distributions of assessed variables and analyses of their parameters could be conducted and respondents could be grouped with respect to analyzed characteristics. Subsequently, statistical differences between these groups were assessed using $\chi^{2}$. Statistical analysis was carried out using PASW Statistics 18.0.

\section{Results}

The analysis showed that $6.5 \%$ of all participants ( $n=77 ; 7.7 \%$ of females and $3.5 \%$ of males) could have depression according to Kutcher's criteria, whereas $1.5 \%$ of them $(n=18)$ reported suicidal thoughts. Additionally, we observed significant differences in prevalence of depressive symptoms between male and female participants of our study $\left(\chi^{2}=6.880\right.$ at $p$ <0.009). Then, we estimated the effect of having siblings. Here we found that $14 \%$ of respondents were singletons, $54 \%$ of them had either one sister or one brother, $26 \%$ of them had two siblings, while $6 \%$ had three or more siblings. Here the prevalence of depressive symptoms was as follows: $11.5 \%$ for singletons; $5.5 \%$ for subjects with one sister/brother; $6.2 \%$ for students who had two siblings; and 5.4\% for respondents with three or more siblings. Although we did not observe an influence of having brothers or sisters on severity of depressive symptoms $\left(\chi^{2}=7.933\right.$ at $\left.p=0.339\right)$, we could show statistical differences in severity of symptoms between participants who were single- 
tons and subjects who had one $\left(\chi^{2}=7.470\right.$ at $p<0.006)$ or two siblings $\left(\chi^{2}=3.940\right.$ at $\left.p<0.048\right)$. Next, we investigated the role of subjects' permanent place of residence on their depression, yet we could not observe it in our sample $\left(\chi^{2}=1.359\right.$ at $p=0.929$ ) (see Table I for details). Then we analyzed, and confirmed, the influence of participants' major on their symptoms of depression $\left(\chi^{2}=23.71792\right.$ at $\left.p<0.034\right)$. Additionally, we found significant differences between students of psychology and other subgroups such as students of physiotherapy $\left(\chi^{2}=7.390\right.$ at $\left.p<0.0066\right)$ or pharmacy $\left(\chi^{2}=12.74\right.$ at $\left.p<0.0004\right)$; medical $\left(\chi^{2}=8.920\right.$ at $p<0.003)$ or dental students $\left(\chi^{2}=10.460\right.$ at $p<0.001)$; and participants of the M.D. Program in English $\left(\chi^{2}=8.290\right.$ at $\left.p<0.003\right)$. However, other subgroups of students did not differ significantly $(p>0.05)$ (details on participants' major are shown in Table II).

Then, we analyzed the effect of participants' year of study on their depressive symptoms. We found that $34 \%$ of participants were freshmen students, $37 \%$ of them were second year students (sophomores), while the remainder were in their last years of study. There were as many as $13.2 \%$ of freshmen students and $2.7-3.5 \%$ of students in their last years of study whose KADS results indicated depression. Here, we observed the influence of participants' year of study on their depressive symptoms $\left(\chi^{2}=41.87279\right.$ at $\left.p<0.000\right)$ and found significant differences between freshmen students and sophomores $\left(\chi^{2}=23.720\right.$ at $\left.p<0.001\right)$ and students in their last years of study $(p<0.000-0.0006)$.

Subsequently we evaluated the role of current living arrangements in subjects' susceptibility to depression but could not confirm it in the examined sample $\left(\chi^{2}=7.543707\right.$ at $\left.p=0.940\right)$ (the data on respondents' current living arrangements can be found in Table III).

Finally, we assessed the impact of participants' perceived financial status on their symptoms (see Table IV for details). Here we found significant differences between the subgroup of participants who believed their status was poor and those who thought it was average $\left(\chi^{2}=7.670\right.$ at $\left.p=0.006\right)$, good $\left(\chi^{2}=17.940\right.$ at $\left.p<0.001\right)$ and very good $\left(\chi^{2}=22.500\right.$ at $\left.p<0.001\right)$. Furthermore, we found statistically significant differences between respondents with average and good or very good financial status $\left(\chi^{2}=4.970\right.$ at $p=0.026$ and $\chi^{2}=4.380$ at $p=0.036$ respectively). In contrast, we did not find significant statistical differences between subjects

Table I. Participants' permanent place of residence

\begin{tabular}{|lcccc|}
\hline Permanent place of residence & $\begin{array}{c}\text { No. } \\
\text { of participants }\end{array}$ & Percentage & $\begin{array}{c}\text { No. of participants } \\
\text { who met } \\
\text { Kutcher's criteria } \\
\text { for depression } \\
\text { (test score } \geq 6 \text { ) }\end{array}$ & $\begin{array}{c}\text { Percentage of participants } \\
\text { who met } \\
\text { Kutcher's criteria } \\
\text { for depression } \\
\text { (test score } \geq 6 \text { ) }\end{array}$ \\
\hline Rural area & 261 & 22 & 18 & 6.9 \\
\hline A town (population of $<30,000)$ & 296 & 25 & 15 & 5.0 \\
\hline A city (population of 30,000-300,000) & 626 & 53 & 44 & 7.0 \\
\hline Total & 1183 & 100 & 77 & \\
\hline
\end{tabular}

Table II. Data on respondents' major area of study

\begin{tabular}{|lcccc|}
\hline Respondent's major & $\begin{array}{c}\text { No. } \\
\text { of participants }\end{array}$ & Percentage & $\begin{array}{c}\text { No. of participants } \\
\text { who met } \\
\text { Kutcher's criteria } \\
\text { for depression } \\
\text { (test score } \geq 6)\end{array}$ & $\begin{array}{c}\text { Percentage of participants } \\
\text { who met } \\
\text { Kutcher's criteria } \\
\text { for depression } \\
\text { (test score } \geq 6 \text { ) }\end{array}$ \\
\hline Psychology & 95 & 8.0 & 16 & 16.8 \\
\hline Physiotherapy & 100 & 8.5 & 4 & 4 \\
\hline Midwifery & 112 & 9.5 & 9 & 8.0 \\
\hline Nursing & 60 & 5.1 & 4 & 6.6 \\
\hline Pharmacy & 229 & 19.4 & 11 & 4.8 \\
\hline Medicine & 383 & 32.3 & 27 & 7.0 \\
\hline Dentistry & 110 & 9.3 & 3 & 2.7 \\
\hline Medicine (M.D. Program in English) & 94 & 7.9 & 3 & 3.1 \\
\hline Total & 1183 & 100.0 & 77 & \\
\hline
\end{tabular}


Table III. Participants' current living arrangements

\begin{tabular}{|lcccc|}
\hline Current living arrangements & $\begin{array}{c}\text { No. } \\
\text { of participants }\end{array}$ & Percentage & $\begin{array}{c}\text { No. of participants } \\
\text { who met } \\
\text { Kutcher's criteria } \\
\text { for depression } \\
\text { (test score } \geq 6)\end{array}$ & $\begin{array}{c}\text { Percentage of participants } \\
\text { who met } \\
\text { Kutcher's criteria } \\
\text { for depression } \\
\text { (test score } \geq 6 \text { ) }\end{array}$ \\
\hline At parents' home & 243 & 20.5 & 17 & 7 \\
\hline With sister/brother & 41 & 3.5 & 0 & 0 \\
\hline At a dormitory & 210 & 17.8 & 14 & 6.7 \\
\hline Share a flat with a roommate & 547 & 46.2 & 36 & 6.6 \\
\hline Independent rent & 63 & 5.3 & 5 & 7.9 \\
\hline With family (husband or wife) & 30 & 2.5 & 0 & 0 \\
\hline Own flat & 49 & 4.1 & 5 & 10.2 \\
\hline Total & 1183 & 99.9 & & \\
\hline
\end{tabular}

Table IV. Data on respondents' perceived financial status

\begin{tabular}{|lcccc|}
\hline $\begin{array}{l}\text { Descriptor used to describe } \\
\text { one's own financial status }\end{array}$ & $\begin{array}{c}\text { No. } \\
\text { of participants }\end{array}$ & Percentage & $\begin{array}{c}\text { No. of participants } \\
\text { who met } \\
\text { Kutcher's criteria } \\
\text { for depression } \\
\text { (test score } \geq 6)\end{array}$ & $\begin{array}{c}\text { Percentage of participants } \\
\text { who met } \\
\text { Kutcher's criteria } \\
\text { for depression } \\
\text { (test score } \geq 6)\end{array}$ \\
\hline Very poor & 3 & 0.3 & 0 & 0 \\
\hline Poor & 14 & 1.2 & 5 & 35.7 \\
\hline Average & 300 & 25.4 & 28 & 9.3 \\
\hline Good & 636 & 53.7 & 34 & 5.3 \\
\hline Very good & 230 & 19.4 & 10 & 4.3 \\
\hline Total & & 100 & 77 & \\
\hline
\end{tabular}

with good and very good financial status $\left(\chi^{2}=\right.$ at $p=0.612$ ).

\section{Discussion}

Depression has often been reported as one of the most important mental health problems in the student population [19-21]. Yet, it often remains undetected or undertreated, partly because investigators and clinicians lacked time-efficient sensitive and valid self-report tools to evaluate its symptoms [22]. Instead, respondents were often administered scales and inventories which were designed for other age groups. Effective diagnosis of depressive symptoms in the student youth became possible after KADS had been developed [26]. KADS, which was an extensively used scale to monitor symptoms of depression before it became severe, had originally been validated on a group of 12-19 year olds but could be used in the 12-22 age group [26]. We validated the test for the population of youth aged 1225 with very good psychometric properties. Furthermore, we found that validation parameters of the Polish version corresponded to those obtained during validation of the original version [27]. There were other scales available such as the Montgomery-Asberg Depression Rating Scale (MADRS) or Hamilton Rating Scale for Depression (HAM-D), which could be applied but they were time-consuming and could be administered only by trained and experienced clinicians $[28,29]$. Kutcher's KADS, however, was short, based on self-report and characterized by clear assessment criteria. Consequently, application of the KADS allowed for time- and costeffective screening of depressive symptoms in large numbers of subjects. In the present study we used the KADS to assess the prevalence of depression and suicidal thoughts in students of medicine or similar faculties such as dentistry, midwifery and nursing, physiotherapy, pharmacy or psychology. We also examined the association between symptoms of depression and demographic agents such as participants' gender, having brothers or sisters, background (rural/small town or urban permanent place of residence), perceived financial status, current living arrangements or year and major area of study. Our results showed that females had a much higher risk of depression than males $(7.7 \%$ of females vs. 3.5\% of males). Furthermore, we found statistical differences in prevalence of depressive 
symptoms between male and female respondents. This observation is in line with other studies which documented that, starting from early adolescence, females were nearly twice as likely to suffer from depression as males. This well-known inequality has been attributed to biological, psychological or social factors (e.g. hormonal action, low self-esteem, maladaptive coping styles, lower social status, or sense of mastery and personal power) [30, 31].

Next, we evaluated the effect of having siblings and found that depressive symptoms were much more prevalent in singletons than in subjects who had brothers or sisters. Our results cannot be related to results presented in other articles because the problem has not been analyzed yet. However, one may hypothesize here that communication with brothers or sisters may have a buffering effect against depressive symptoms because of support, consolation and, perhaps, a sense of belonging they provide, even if they live far away [32].

In the present study we found that participants' self-reported financial status influenced symptoms of depression in the analyzed sample, i.e. subjects with lower economic status had significantly higher depression scores than the respondents who considered themselves wealthier. This finding is consistent with the results of other research studies showing that low socioeconomic status is associated with higher incidence of mental health problems [15, 21, 25]. Nonetheless, our results contradict the data presented by Yeong et al., who analyzed the association between socioeconomic status and depression in medical students living in Korea. Yeong's team found that medical students with a mid-range household income had a significantly lower risk of depression compared to those with higher household incomes [24]. Still, one may note here that Korean students may apply for scholarships or loans so they do not have to depend on financial help from their parents. Our analysis also showed that the participants who were freshmen students had dramatically higher depression scores than more advanced students. In fact, the first year at college has been identified as a critical period when students experience high levels of stress which may, in turn, lead to depressive episodes. According to some authors, excessive stress in freshman students may also be manifested by increases in overweight status due to overeating, higher risk for injury, or frequent drinking [33-37]. Indeed, the transition to college is believed to be a critical stage of life when an adolescent not only has to adjust to new methods of learning and grading but also to adapt to university lifestyle. Furthermore, newcomer college students may find it difficult to accomplish developmental tasks connected with functioning in a peer group and successful academic performance because these tasks may often interfere with each other. Mikolajczyk et al. also tried to explain this phenomenon and suggested that depressive symptoms could be triggered by physical separation from one's parents [21]. In line with this hypothesis, Small et al. demonstrated that increased communication between first-year college students and their parents positively influenced negative health behaviors among the former [38]. Our study also analyzed the relationship between participants' major area of study and their depression levels. We found that psychology students were significantly more depressive than other subjects. This phenomenon was also analyzed by Peluso et al., who reported that $33 \%$ of Canadian graduate students of psychology had symptoms of clinical depression which could not be explained by workload or difficulty of the curriculum [39]. Indeed, students of psychology have significantly more depressive symptoms than medical students, although their study is undoubtedly very demanding (many more exams, tests and hours of study). In fact, depression in medical students in our study was less frequent (3.1\%) compared to results presented by other authors [40, 41]. One may add here that our finding confirms a stereotypical belief, according to which students of psychology choose this area of study to find help for their personal problems. To find an explanation one may also try to analyze how the system of university level teaching or patterns of communication between lecturers and students influence students' mental health. Perhaps the system of teaching psychology which involves self-analysis and selfreflection attracts students with a tendency to rumination and negative thinking. Perhaps some characteristics of the system of teaching medicine, teacher-student relationships or the atmosphere during classes positively affect medical students' wellbeing and, at the same time, alleviate the negative effect of workload, stress and high academic pressure. Future investigations are necessary to find the answers to these questions.

This study has its limitations. First, only one method, i.e. the KADS, was used to observe factors associated with depression. We selected this test because the KADS was designed to screen the risk for depression so it was appropriate for population studies. However, in order to assess intensity of symptoms of depression, other clinician-administered diagnostic methods should be applied. Second, differences could be indicated in the mean age between participants of the original normalization group for the KADS and the respondents of our study. One can observe that the test was originally normalized and validated in a group of adolescent high-school children while we administered it in a group of young adults (students). However, we validated the test for university-age youth and 
found that the KADS could also be utilized in young adults.

In conclusion, susceptibility to depression fluctuates throughout the course of study and depends on the student's major. Risk factors for student depression also include gender and financial status.

\section{Conflict of interest}

The authors declare no conflict of interest.

\section{References}

1. Cuijpers P, Beekman ATF, Reynolds CF. Preventing depression: a global priority. JAMA 2012; 307: 1033-4.

2. Khan TM, Sulaiman SAS, Hassali MA. Factors associated with suicidal behaviour among depressed patients in Penang, Malaysia. Arch Med Sci 2012; 8: 697-703.

3. Ustun TB, Kessler RC. Global burden of depressive disorders: the issue of duration. Br J Psychiatry 2002; 181: 181-3.

4. Beautrais AL. Risk factors for suicide and attempted suicide among young people. Aust NZ J Psychiat 2010; 34 420-36.

5. Cash SJ, Bridge JA. Epidemiology of youth suicide and suicidal behavior. Curr Opin Pediatr 2009; 21: 613-9.

6. Szumilas M, Kutcher SP. Youth and suicide. CMAJ fact sheet. CMAJ 2008; 178: 286.

7. Verona E, Javdani S. Dimensions of adolescent psychopathology and relationships to sicide risk indicators. J Youth Adolesc 2011; 40: 958-71.

8. Fergusson DM, Boden JM, Horwood LJ. Recurrence of major depression in adolescence and early adulthood, and later mental health, educational and economic outcomes. Br J Psychiatry 2007; 191: 335-42.

9. Rao U, Chen L. Characteristics, correlates, and outcomes of childhood and adolescent depressive disorders. Dialogues Clin Neurosci 2009; 11: 45-62.

10. Zisook S, Lesser I, Stewart JW, et al. Effect of age at onset on the course of major depressive disorder. Am J Psychiatry 2007; 164: 1539-46.

11. Angold A, Costello EJ. Depressive comorbidity in children and adolescents: empirical, theoretical, and methodological issues. Am J Psychiat 1993; 150: 1779-91.

12. Birmaher B, Ryan ND, Williamson DE, et al. Childhood and adolescent depression: a review of the past 10 years. Part I. J Am Acad Child Adolesc Psychiatry 1996; 35: 1427-39.

13. Giletta M, Scholte RH, Prinstein MJ, Engels RC, Rabaglietti E, Burk WJ. Friendship context matters: examining the domain specificity of alcohol and depression socialization among adolescents. J Abnorm Child Psychol 2012; 40: 1027-43.

14. Kessler RC, Avenevoli S, Ries-Merikangas K. Mood disorders in children and adolescents: an epidemiologic perspective. Biol Psychiatry 2001; 49: 1002-14.

15. Lorant V, Deliege D, Eaton W, Robert A, Philippot P Ansseau M. Socioeconomic inequalities in depression: a metaanalysis. Am J Epidemiol 2003; 157: 98-112.

16. Mendelson T, Kubzansky LD, Datta D, Buka SL. Relation of female gender and low socioeconomic status to internalizing symptoms among adolescents: a case of double jeopardy? Soc Sci Med 2008; 66: 1284-96.

17. Rutter M, Kim-Cohen J, Maughan B. Continuities and discontinuities in psychopathology between childhood and adult life. J Child Psychol Psychiatry 2006; 47: 276-95.
18. Zalsman G, Oquendo MA, Greenhill L, et al. Neurobiology of depression in children and adolescents. Child Adolesc Psych Clin N Am 2006; 15: 843-68.

19. Arria AM, O'Grady KE, Caldeira KM, Vincent KB, Wilcox HC, Wish ED. Suicide ideation among college students: a multivariate analysis. Arch Suicide Res 2009; 13: 230-46.

20. Bond L, Toumbourou J, Thomas L, Catalano RF, Patton G. Individual, family, school and community risk and protective factors for depressive symptoms in adolescents: a comparison of risk profiles for substance use and depressive symptoms. Prev Sci 2005; 6: 73-88.

21. Mikolajczyk RT, Maxwell AE, Naydenova V, Meier S, Ansari WE. Depressive symptoms and perceived burdens related to being a student: survey in three European countries. Clin Pract Epidemiol Ment Health 2008; 4: 19.

22. Tjia J, Givens JL, Shea JA. Factors associated with undertreatment of medical student depression. J Am Coll Health 2005; 53: 219-24.

23. Goebert D, Thompson D, Takeshita J, et al. Depressive symptoms in medical students and residents: a multischool study. Acad Med 2009; 84: 236-41.

24. Jeong Y, Kim JY, Ryu JS, Lee KE, Ha EH, Park H. The Associations between social support, health-related behaviors, socioeconomic status and depression in medical students. Epidemiol Health 2010; 32: 1-8.

25. Mojs E, Warchol-Biederman K, Samborski W. Prevalence of depression and suicidal thoughts amongst University Students in Poznan, Poland. Psychology 2012; 2: 132-5.

26. LeBlanc JC, Almudevar A, Brooks SJ, Kutcher S. Screening for adolescent depression: comparison of the Kutcher Adolescent Depression Scale with the Beck Depression Inventory. J Child Adolesc Psychopharmacol 2002; 12: 113-26.

27. Mojs E, Bartkowska W, Kaczmarek LD, Ziarko M, Bujacz A, Warchoł-Biedermann K. Psychometric properties of the Polish version of the brief version of Kutcher Adolescents Depression Scale. Psych Pol 2015; 49: 135-44.

28. Kang HJ, Stewart R, Kim JM, et al. Comparative validity of depression assessment scales for screening poststroke depression. J Affect Disord 2013; 147: 186-91.

29. Furukawa T. Assessment of mood. Guides for clinicians. J Psychosom Res 2010; 68: 581-9.

30. Nolen-Hoeksema S. Gender differences in depression. Curr Dir Psychol Sci 2001; 10: 173-6.

31. Wilhelm K, Roy K, Mitchell P, Brownhill S, Parker G. Gender differences in depression risk and coping factors in a clinical sample. Acta Psychiatr Scand 2002; 106: 45-53.

32. Sargent J, Williams A, Hagerty B, Lynch-Sauer J, Hoyle K. Sense of belonging as a buffer against depressive symptoms. J Am Psychiatr Nurses Assoc 2002; 8: 120-9.

33. Egan KG, Moreno MA. Prevalence of stress references on College Freshmen Facebook Profiles. Comput Inform Nurs 2011; 29: 586-92.

34. Gow RW, Trace SE, Mazzeo SE. Preventing weight gain in first year college students: an online intervention to prevent the "freshman fifteen". Eat Behav 2010; 11: 33-9.

35. Hildebrandt H, Nübling M, Candia V. Increment of fatigue, depression, and stage fright during the first year of highlevel education in music students. Med Probl Perform Art 2012; 27: 43-8.

36. Smith-Jackson T, Reel JJ. Freshmen women and the "Freshman 15": perspectives on prevalence and causes of college weight gain. J Am Coll Health 2012; 60: 14-20.

37. Méndez-Hernández P, Dosamantes-Carrasco D, Lamure $M$, et al. Weight-loss practices among university students in Mexico. Int J Public Health 2010; 55: 221-5. 
38. Small ML, Morgan N, Abar C, Maggs JL. Protective effects of parent-college student communication during the first semester of college. J Am Coll Health 2011; 59: 547-54.

39. Peluso DL, Carleton RN, Asmundson GJG. Depression symptoms in Canadian psychology graduate students: do research productivity, funding, and the academic advisory relationship play a role? Can J Behav Sci 2011; 43: 119-27.

40. Quince TA, Wood DF, Parker RA, Benson J. Prevalence and persistence of depression among undergraduate medical students: a longitudinal study at one UK medical school BMJ Open 2012; 2: pii: e001519.

41. Sidana S, Kishore J, Ghosh V, Gulati D, Jiloha RC, Anand T. Prevalence of depression in students of a medical college in New Delhi: a cross-sectional study. Australasian Med J 2012; 5: 247-50. 